\title{
Development of Cloud Based Demand Forecasting System: A Case Study in Stationery Industry
}

\author{
Pindy Muliady ${ }^{1}$, Prio Utomo ${ }^{2}$, Friska Natalia ${ }^{3}$ \\ \{pindy.muliady@student.umn.ac.id ${ }^{1}$, prio.utomo@umn.ac.id², friska.natalia@umn.ac.id ${ }^{3}$ \} \\ Technology Management Department, Multimedia Nusantara University ${ }^{123}$
}

\begin{abstract}
Stationery industry has been facing inventory problems. Having too much unsold inventory leads to increasing of warehousing cost while not having enough inventory will cause lost sales. We propose a digital transformation project, using Amazon Forecasting to make a better demand prediction so company can solve these problems. Framework used in this paper is Digital Maturity Model from TM Forum. Amazon Forecasting will produce forecast scenario based on the data provided. Finally, we proposed a digital roadmap to help company execute this project. Based on the research, it can be concluded that cloud-based demand forecasting is feasible to to solve inventory problems as the technicality requirement and cost needed is affordable by small medium enterprises. By using AWS, company can have better prediction without having an expertise in forecasting technique. The outcomes of this research can be used by other company to plan digital transformation in forecasting.
\end{abstract}

Keywords: Forecasting, Digital Transformation, Digital Maturity Model, Cloud Based Forecasting

\section{Introduction}

Stationery and office supplies industry in Indonesia has been growing for the last few years. Based on data from Ministry of Trade, number of imported printing products had increase from USD 96.8 million in 2015 to USD 197.7 million in 2018. Companies has been using the push marketing strategy to compete. Push process operate in an uncertain environment in which customer demand is not yet known [1]. Without using any data, it is very challenging to make an accurate prediction for future demand.

Retail industry has been facing inventory problem such as having too little inventories that cause company to lose sales opportunity. Lost sales are those selling opportunities that a firm lost because an item was out of stock, or a firm does not carry a particular brand, line of merchandise, and any other possibility that causes the seller to lose the opportunity to sell [2]. On the other hand, sometimes a company can face inventory overstocking which results in increasing operational cost. Demand for each product will also differ from one branch/store with another. Moving goods from a branch that run into overstocking problem to the one who is having understocking problem takes time and money. These conditions effect cash flow of a company. Bad cash flow management can make a profitable company goes bankrupt, especially because of a high operational cost to [3]. Deciding quantity of items to stock plays an important role to ensure profitability.

Small medium enterprises need an agile, ambidextrous innovation management in order to remain competitive in times of digitalization [4]. It is one of the reasons why companies do digital transformation. Analysing new data manually takes a lot of time, effort, and people. Therefore, technology application in a business process is a path many companies choose to keep them agile and responsive to change. But small medium companies struggle to initiate their digital journey as they lack resources and expertise [5].

Cloud computing technology is used to store and access data as well as applications over the network in a private storage hosting space [6]. Cloud computing is viewed as one of the options to help company makes a better decision in a faster and cheaper way. National Institute of Standards and Technology (NIST) proposed the definition of cloud computing as a model for enabling convenient, on-demand network access to a shared pool of configurable computing resources (e.g. networks, servers, storage, applications and services) that can be rapidly provisioned and released with minimal management effort or service provider interaction. 


\section{Case Study}

The company used in this case study is a retail company in stationery industry, established since 2010. They serve two customer segments with two different business model. These customers are called dropshipper and reseller. In short, dropshipper are customers who doesn't have their own stock. When dropshipper got order from customer, the detail will be forwarded to company, and they will handle the order processing. Reseller buy products from the company and stock them in warehouse/store, then they directly sell the products to customer. Since reseller buy in bulks from company, quantity of items per purchase is bigger than dropshipper.

Company sells the same product to both of these customers; this often leads to a situation where bestselling item sold quickly and customer will complain for not being able to get enough quantity to meet their customer's demands. Not only company is losing opportunity to make sales, customer satisfaction is also hurt. This become a concern as building up relationship and trust from customer takes a long time to begin with. On the other hand, if company has too many stocks of a particular item and it doesn't sell well, these products become a burden for the team. They need to find a way to sell them through promotion or campaign, sometimes even cutting the price significantly and selling at a loss. As [7] stated, stockout or overfilling the warehouse may cause great loss for companies, such as huge cost and low customer satisfaction and loyalty. Management think these problems are the result of inaccurate demand forecasting. Thus, having a good system to make better prediction is crucial to solve inventory problem.

\section{Forecasting}

Digital transformation has been done several times in the company. Starting from receiving customer's order from messaging application like WhatsApp or email, now they have their own order management system. The system is always updated with features needed by customers and internal management to handle daily operations. Forecasting needs specific skill such as statistic knowledge. With limited resources, the company decides to use cloud-based forecasting tool that is already available in the market rather than creating their own tool. Cloud based application offers certain services that will only charge the user based on usage, so even small enterprise can use these services with small investment.

Purpose of forecasting is to obtain a fairly accurate estimation of future demand for a product or service given historical data and the current state of the environment (e.g., political, social, economic) to plan and organize businesses accordingly [8]. Demand forecasting helps inventory planning and excess inventory reduction in a company [9]. Time series analysis is one of methods used in demand forecasting. [2] suggest using this method to reduce lost sales. Some companies still do demand forecasting without collecting and processing any data. They rely on a person or group of people who is considered experienced in their field and knows the market in the industry.

The cloud computing, as a fast advancing technology, is increasingly being used to host many business or enterprise applications [10]. Nowadays, there are many cloud-based forecasting tools available offering wide range of features and benefits. Companies can transform demand forecasting process from manual to digital by using these tools according to their needs. This transformation might face some challenges both internal and external. Company who is not used to doing business digitally may not have data recorded in database, or the data available isn't ready to be used directly in the tool. Changing business environment can reduce the accuracy of forecast, for example the spread of COVID-19 virus that affects supply chain demand globally [11].

Four forecasting tools were considered to be used by the company. Based on the features, pricing and forecasting algorithm provided, tool from Amazon Web Service (AWS) were chosen. It has capability to do time series forecast based on the data provided. After uploading data to AWS, it will train a predictor, then needed forecast can be generated.

There are two KPI to measure whether the implementation is successful. Value of inventory available in the warehouse will decrease, at the same time sales revenue will increase. The company has set a minimum inventory value required and aims to decrease available inventory to that level.

\section{Digital Maturity Model}

Digital transformation is the integration of digital technologies and new business models into all areas of resulting in major changes to how industries function and how they provide value to customers [12]. In this digital 
transformation project, company refers to Digital Maturity Model (DMM) framework from TM Forum. There are 5 dimensions, 24 sub dimensions and more than 100 indicators that can be measured.

Customer dimension measures how forecasting is useful not only to forecast demand for the company, but also to supply information that can be used by customer to make better decision and strategy in the future. Strategy dimension measures how forecasting used as a strategy to provide new competitive advantage and improve brand image. Technology dimension measure the usage of new technology to store data while keeping them secure from internal and external threats. Operation dimension consist of analysing data and data processing automation. While culture dimension will show how far employee understand and contribute to digital transformation project in the company.

\section{Business Capabilities}

This project will change how company deciding quantity of products needed to be ordered from supplier. Initially, it was done by one of the directors based on experience and hunch. For example, in the previous period, 5 boxes of notebook were ordered, and they were all sold out after a few months, then next time, 7 boxes will be ordered. If all of these are sold out, then the quantity will be increased again, and so on. Basically, demand forecasting was done manually without analysing data. This will be changed after the digital transformation project is finished. Before deciding the quantity, demand for a period of time will be forecasted using the AWS Forecasting tool. After demand prediction number is generated, they still need to compare it with available stock at that time. The purpose of comparing the numbers is to avoid overstocking for an item that is still available on the shelf.

Company will have new business capabilities after this digital transformation project is done. These capabilities including:

- Customer relationship management. Based on customer's purchase history, they can get item's recommendation and the number needed based on forecasting. This will help customer with overstocking and lost sales problem.

- Strategic planning. Sales division can plan strategies in advance to push products with high demand and increasing company's revenue. With higher forecasting accuracy, director will be able to negotiate price with supplier without worrying about overstocking.

- Market intelligence. With more accurate information, company will get a better understanding of market situation and demand. It is useful for both short term and long-term planning.

- Demand prediction automation. Using available tool, company can get better forecasting result without too much effort.

- Organizational development. The whole organization will have a role in this project. They will be briefed on what is the impact of this project for stakeholder of company and how can they contribute.

\section{Methodology}

To measure the dimensions mentioned above, 29 indicators that are considered relevant with this project were chosen. Each indicator will be represented with one question and every question is given five options, from 1-5. There is an explanation for what these numbers mean to avoid confusion from the correspondent. The explanation is based on TM Forum's DMM standard.

Employees, partners, customers and suppliers were asked to fill questionnaire. But because there are many technical aspects being measured which most correspondent is not familiar with, the answer from questionnaire were used as feedback for the directors, not to measure the DMM level directly. DMM level will be decided by directors only.

There are 21 respondents from employees, customers, partners and suppliers. The results will be tested for validity using Pearson method and reliability using Cronbach's Alpha method.

After reviewing company's situation and feedback from stakeholders, it is decided that the DMM level are:

- Customer dimension: level 1 (initiating)

- Strategy dimension: level 1 (initiating) 
- $\quad$ Technology dimension: level 1 (initiating)

- Operations dimension: level 1 (initiating)

- Culture dimension: level 2 (emerging)

Forecasting itself will be divided into 3 phases:

- $\quad$ Phase 1

Company will forecast demand for each product category to tackle the two main problems mentioned above. The director will be the only user of forecasting phase one.

- $\quad$ Phase 2

Forecast will be done per category per sales area, forecast result will be shared with customers. This information will help them with planning a better targeted advertising strategy, or to gain insight of products' demand in their area. Knowing the demand will especially help those who have an offline store.

- $\quad$ Phase 3

Customers' product demand will be predicted in phase 3 . With a detailed information, they can avoid inventory overstocking and lost sales. Company will also use this to give customer a better item recommendation.

To achieve these 3 phases, improvement is needed on all dimensions. Based on business capabilities of each phase, company decided that DMM level needs to improve to level that can be seen in table 1.

Table 1. DMM level for each forecasting phase.

\begin{tabular}{|l|c|c|c|c|}
\hline Dimension & $\begin{array}{c}\text { Current } \\
\text { DMM Level }\end{array}$ & $\begin{array}{c}\text { Phase 1 } \\
\text { Forecasting }\end{array}$ & $\begin{array}{c}\text { Phase 2 } \\
\text { Forecasting }\end{array}$ & $\begin{array}{c}\text { Phase 3 } \\
\text { Forecasting }\end{array}$ \\
\hline Customer & 1 & 1 & 2 & 2 \\
\hline Strategy & 1 & 2 & 2 & 3 \\
\hline Technology & 1 & 2 & 3 & 3 \\
\hline Operations & 1 & 2 & 2 & 3 \\
\hline Culture & 2 & 2 & 3 & 3 \\
\hline
\end{tabular}

Based on forecasting phases mentioned above, the future maturity level expected are:

- Customer dimension: level 2 (emerging)

- $\quad$ Strategy dimension: level 3 (performing)

- Technology dimension: level 3 (performing)

- Operations dimension: level 3 (performing)

- Culture dimension: level 3 (performing)

\section{Financial Analysis}

Company has set a target for each forecasting phase. Inventory value should decrease, and profit should increase in each phase, as shown in table 2. 
Table 2. Forecasting financial benefit.

\begin{tabular}{|l|r|r|r|}
\hline \multicolumn{1}{|c|}{ KPI } & $\begin{array}{c}\text { Forecasting } \\
\text { Phase 1 }\end{array}$ & $\begin{array}{c}\text { Forecasting } \\
\text { Phase 2 }\end{array}$ & $\begin{array}{c}\text { Forecasting } \\
\text { Phase 3 }\end{array}$ \\
\hline Inventory Value & $7.20 \%$ & $11.50 \%$ & $13.04 \%$ \\
\hline Warehouse Cost Saving & $3.20 \%$ & $4.80 \%$ & $4.80 \%$ \\
\hline & & & \\
\hline Sales Profit & $16.00 \%$ & $22.40 \%$ & $25.30 \%$ \\
\hline & & & \\
\hline Nett Profit & $16.10 \%$ & $22.51 \%$ & $25.13 \%$ \\
\hline
\end{tabular}

Available stock is reduced until the minimum limit set by the company. It should not go below the minimum limit because there can be a problem that delay the shipping process from supplier to warehouse. If it happens, company need to have a certain amount of inventory to keep the business running.

With less inventory, warehouse cost can be reduced. Warehousing cost per inventory has been calculated and for the first phase, company can save 3.2\%, while in the second and third phase company can save $4.8 \%$. Meanwhile, sales profit can increase by $16 \%$ in the first phase, $22.4 \%$ in the second phase, and $25.3 \%$ in the third phase. These two benefits combined, accounts for $16.1 \%$ increase in nett profit in the first phase, $22.51 \%$ in the second phase and $25.13 \%$ in the third phase.

\section{Forecasting Result}

There are a few steps to be to start using AWS Forecasting tool (Fig. 1). First, user need data sales history in CSV format. Upload this data to create a dataset group and choose a forecasting domain, in this case, we chose retail domain. The next step is creating a dataset group which include uploading the data we have prepared previously, at least this data contain item name or number, sales date and quantity. We can add other data based on what we need. Then we need to train a predictor, here we can choose forecasting algorithm from some available options provided by Amazon. The last step is to make a forecasting. These processes will takes time depend on how much data we input to the system.

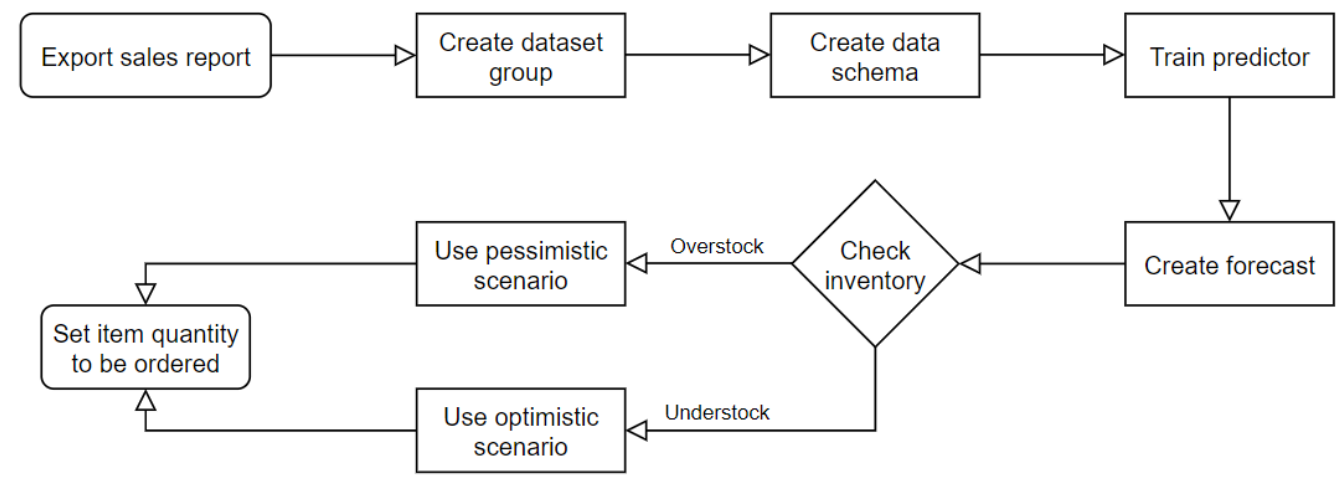

Fig. 1. Forecasting flow chart

Forecasting has been done using sales data from 2016 - 2019 to predict demand for January 2020 March 2020 on one product category. Result from AWS can be seen in Fig. 2. 


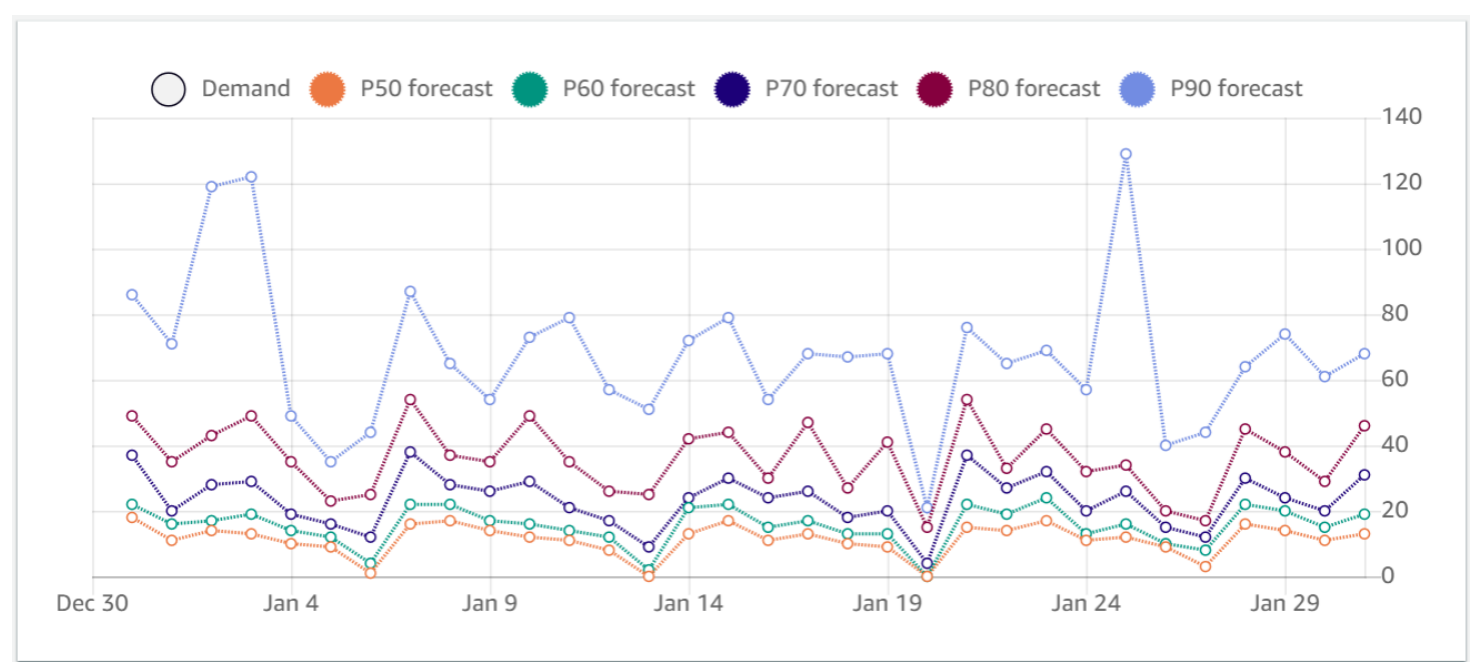

Fig. 2. Forecasting result

There are five prediction made, from P50 until P90. P50 is the pessimistic scenario while P90 is the optimistic one. If this category is overstocked in the warehouse, then it is recommended to use the pessimistic scenario. On the other hand, if this category is understocked, then use the optimistic scenario.

Comparison between prediction made by AWS and sales number from company can be seen in table 3 .

Table 3. Sales data and prediction comparison

\begin{tabular}{|l|r|r|r|r|r|c|}
\hline \multicolumn{1}{|c|}{ Month } & Sales Data & \multicolumn{1}{c|}{ P50 } & \multicolumn{1}{c|}{ P60 } & \multicolumn{1}{c|}{ P70 } & P80 & \multicolumn{1}{c|}{ P90 } \\
\hline January & 1,254 & 344 & 476 & 712 & 1,110 & 2,082 \\
\hline February & 901 & 351 & 456 & 706 & 1,056 & 2,473 \\
\hline March & 1,437 & 305 & 445 & 621 & 931 & 1,794 \\
\hline
\end{tabular}

Difference between each prediction is shown in table 4 .

Table 4. Difference for each scenario.

\begin{tabular}{|l|r|r|r|r|r|}
\hline Month & \multicolumn{1}{|c|}{ P50 } & \multicolumn{1}{c|}{ P60 } & \multicolumn{1}{c|}{ P70 } & \multicolumn{1}{c|}{ P80 } & \multicolumn{1}{c|}{ P90 } \\
\hline January & 910 & 778 & 542 & 144 & -828 \\
\hline February & 550 & 445 & 195 & -155 & -1572 \\
\hline March & 1,132 & 992 & 816 & 506 & -357 \\
\hline
\end{tabular}

Positive number means the prediction is less than the sales number and negative number means the prediction is more than the sales number.

\section{Conclusion}

Forecasting is proposed as a solution to solve inventory overstock and lost sales problem in retail industry. To transform decision making process from manual to data based, valid and reliable data is needed. This data will be used to predict a more accurate future demand that helps companies grow their business. There will be some possible outcomes provided by forecasting tool that can be used based on current situation on the company There are two KPIs being monitored to measure the success of this project, sales revenue and the number of inventory available in warehouse.

As for limitation of this study, we only used data from one company which can't represent the whole stationery industry. Especially because not all companies have the same business model. For future research, we recommend to study about pricing strategy focused on how to set the price so company can get most profit for each product category. 


\section{References}

[1] S. Sarbjit, "Study on Push/ Pull Strategy Decision Taken by Organizations for Their Products and Services," Univers. J. Manag., vol. 5, no. 10, pp. 492-495, 2017, doi: 10.13189/ujm.2017.051004.

[2] J. E. Jarrett, “An Analysis of Lost Sales," Manag. Econ. Res. J., vol. 01, no. December, p. 28, 2015, doi: 10.18639/merj.2015.01.159412.

[3] D. Stice, E. K. Stice, and J. D. Stice, "Cash Flow Problems Can Kill Profitable Companies," Int. J. Bus. Adm., vol. 8, no. 6, p. 46, 2017, doi: 10.5430/ijba.v8n6p46.

[4] N. Niewöhner, L. Asmar, F. Wortmann, D. Röltgen, A. Kühn, and R. Dumitrescu, "Design fields of agile innovation management in small and medium sized enterprises," Procedia CIRP, vol. 84, pp. 826831, 2019, doi: 10.1016/j.procir.2019.04.295.

[5] M. Fischer, F. Imgrund, C. Janiesch, and A. Winkelmann, "Strategy archetypes for digital transformation: Defining meta objectives using business process management," Inf. Manag., vol. 57, no. 5, p. 103262, 2020, doi: 10.1016/j.im.2019.103262.

[6] M. T. Amron, R. Ibrahim, N. A. Abu Bakar, and S. Chuprat, "Determining factors influencing the acceptance of cloud computing implementation," Procedia Comput. Sci., vol. 161, pp. 1055-1063, 2019, doi: 10.1016/j.procs.2019.11.216.

[7] M. Rahimi, A. Baboli, and Y. Rekik, "Multi-objective inventory routing problem: A stochastic model to consider profit, service level and green criteria," Transp. Res. Part E Logist. Transp. Rev., 2017, doi: 10.1016/j.tre.2017.03.001.

[8] G. Merkuryeva, A. Valberga, and A. Smirnov, "Demand forecasting in pharmaceutical supply chains: A case study," Procedia Comput. Sci., vol. 149, pp. 3-10, 2019, doi: 10.1016/j.procs.2019.01.100.

[9] O. Nnamdi, "Strategies for managing excess and dead inventories: A case study of spare parts inventories in the elevator equipment industry," Oper. Supply Chain Manag., vol. 11, no. 3, pp. 128139, 2018, doi: 10.31387/oscm0320209.

[10] P. Kumari and P. Kaur, "A survey of fault tolerance in cloud computing," J. King Saud Univ. - Comput. Inf. Sci., 2018, doi: 10.1016/j.jksuci.2018.09.021.

[11] D. Ivanov, "Predicting the impacts of epidemic outbreaks on global supply chains: A simulation-based analysis on the coronavirus outbreak (COVID-19/SARS-CoV-2) case," Transp. Res. Part E Logist. Transp. Rev., vol. 136, no. March, p. 101922, 2020, doi: 10.1016/j.tre.2020.101922.

[12] S. Albukhitan, "Developing Digital Transformation Strategy for Manufacturing," Procedia Comput. Sci., vol. 170, pp. 664-671, 2020, doi: 10.1016/j.procs.2020.03.173. 